\title{
Seção de Revisão de Livros
}

Neste número da revista Pesquisa Operacional é apresentada a resenha do livro Practical Time Series, de Gareth Janacek, escrita por Reinaldo Castro Souza, Doutor em Estatística pela University of Warwick, Inglaterra, e Professor Titular do Departamento de Engenharia Elétrica da PUC/RJ.

Ronaldo Rocha Bastos

Departamento de Estatística

Universidade Federal de Juiz de Fora

Juiz de Fora - MG

rrbastos@estatistica.ufjf.br

Practical Time Series Gareth Janacek, $1^{\mathrm{a}}$ ed., Arnold Texts in Statistics, London: Arnold Publishers, ISBN 0-340-71999-0, 2001, xiii + 156 pp., brochura.

Informações: http://www.arnoldpublishers.com

Não resta qualquer sombra de dúvidas sobre a importância dos anos setenta para o desenvolvimento e personificação da área de análise e previsão de séries temporais. E também é consenso entre os especialistas da área que este saldo se deve à grandiosa obra dos ingleses G.E.P. Box \& G. Jenkins. A partir deste trabalho o que se viu foi o crescimento a passos largos das publicações especializadas, dos periódicos específicos (como, por exemplo, o Journal of Forecasting, o International Journal of Forecasting, o Journal of Time Series, dentre outros), os congressos e simpósios especializados (como, por exemplo, os ISF's International Symposium on Forecasting; as ESTE's - Escolas de Séries Temporais no Brasil, dentre outros). Dessa forma, e como conseqüência imediata, encontramos hoje nas estantes reservadas à Estatística das livrarias científicas do mundo um número expressivo de livros textos dedicados a área de séries temporais. Neste contexto se insere a presente obra, objeto da revisão que se segue.

"Yet another time series book?", é a primeira colocação do autor na página inicial do livro. Que se trata de outro livro de séries temporais ninguém questiona, porém, os objetivos da obra conforme proposto pelo autor, ou seja, um texto introdutório com compromisso claro com a aplicação são, na minha visão, parcialmente atingidos. De inovador mesmo e, porque não, meritoso, é a ferramenta computacional utilizada pelo autor para ilustrar os diversos exemplos e desenvolvimentos da obra. Foi por ele utilizado um tipo de "freeware", desenvolvido por Robert Gentleman \& Ross Ihaka, conhecido simplesmente como R. Todos os procedimentos e rotinas apresentados no texto foram programados em $\mathbf{R}$, não sendo utilizado qualquer um dos já tradicionais softwares de análise e previsão de séries temporais de uso corrente. Para maiores detalhes sobre o $\mathbf{R}$, o autor fornece o website onde o leitor poderá encontrar informações detalhadas do mesmo, ou seja: http://www.ci.tuwien.ac.at/R/contents.html 
Com relação à organização e conteúdo do texto, este é composto de 9 capítulos, sendo 8 dedicados aos tópicos específicos de séries temporais e um capítulo voltado para a descrição da linguagem $\mathbf{R}$ e das rotinas específicas desenvolvidas nesta linguagem pelo autor. No que concerne aos 8 capítulos teóricos, estes foram assim divididos:

O capítulo 1, denominado de introdução, contém descrições e conceitos básicos de séries temporais, procedimentos de suavização como médias móveis, vizinho mais próximo e os kernels para suavizar séries. Ao final do capítulo o autor fornece uma lista de exercícios numéricos com ilustrações dos procedimentos.

No capítulo 2 são apresentados, de forma simplificada, os modelos de séries temporais que utilizam o tradicional procedimento de amortecimento/alisamento exponencial. $\mathrm{O}$ autor se detém a uma apresentação bastante superficial dos métodos de Holt e de Winters para séries sazonais. São utilizadas séries reais e as rotinas programadas em $\mathbf{R}$ para auxiliar na apresentação dos resultados. O capítulo é concluído com uma pequena lista de exercícios numéricos.

O capítulo 3, denominado pelo autor de "séries estacionárias", na realidade contém a descrição básica dos elementos teóricos da formulação $\operatorname{ARIMA(p,d,q)~de~Box~\& ~Jenkins.~}$ Os detalhes relativos aos modelos, os padrões das ACF's e PACF's, a formulação das equações de previsão; e uma pequena menção de apenas uma página do modelo SARIMA(p,d,q)x(P,D,Q)s são mostrados de forma também simplificada e sucinta. Como nos anteriores, o capítulo é concluído com uma lista de exercícios gerais.

No capítulo 4 o autor nos surpreende com uma descrição extremamente sucinta da formulação em espaço de estados. Com efeito, em somente 8 páginas o autor descreve a formulação em espaço de estados através do modelo linear dinâmico para observações gaussianas e a forma pela qual os modelos ARIMA de Box \& Jenkins podem ser acomodadas na formulação em espaço de estados. Interessante observar que o autor cita como principais referências bibliográficas no assunto as obras de A. Harvey e a de M. West \& J. Harrison. Entretanto, nada é dito sobre as abordagens adotadas em ambas para o tratamento dos hiperparâmetros, a saber as abordagens clássica e bayesiana. Mas o grande pecado do capítulo é o confuso exemplo da página 55 onde o autor tenta ilustrar a passagem de um $\operatorname{ARMA}(2,3)$ para o espaço de estado. Existem algumas passagens que não estão claras e, mais ainda, com erro na fórmula final. Como nos anteriores, o capítulo é concluído com exemplos ilustrativos.

Chegamos ao capítulo 5 e eis o retorno dos modelos ARIMA(p,d,q) de Box \& Jenkins. Só que neste capítulo, denominado "Ajuste de modelos ARIMA", o autor considera somente os aspectos de ajuste dos modelos; a saber, a identificação estrutural através da ACF e PACF, a estimação dos parâmetros e os testes estatísticos de ajuste do modelo. Todos os procedimentos, inclusive a estimação paramétrica, foram feitos com as rotinas em $\mathbf{R}$ escritas pelo autor. Se a separação em aspectos teóricos e ajuste dos modelos adotada pelo autor é didática, não me parece muito correto intercalar os dois capítulos correspondentes pelo capítulo sobre espaço de estados. Há, sem dúvida, uma quebra na apresentação dos modelos de Box \& Jenkins. Por fim, diferentemente dos outros capítulos, o autor não oferece ao final exercícios para o leitor.

Finalmente, os três próximos capítulos, 6,7 e 8 , são reservados ao domínio da freqüência. $O$ autor inicialmente apresenta os conceitos e definições de séries temporais no domínio da freqüência concentrando na definição do espectro teórico de freqüência de um processo e a representação espectral de uma série. Diferentemente do domínio do tempo, onde o autor 
opta pela parcimônia dos conceitos e dos desenvolvimentos, aqui o autor não se furta de apresentar um vasto material relativo a formulação de uma série no domínio da freqüência. Um exemplo disto é a discussão detalhada sobre o efeito "aliasing" e "freqüência de Nyquist". Já o capítulo 7 é dedicado à estimativa do espectro através do periodograma e o uso das janelas espectrais para a suavização das estimativas das ordenadas do periodograma. O capítulo é recheado de exemplos ilustrativos com dados reais, o que facilita bastante o entendimento do assunto. Em todos eles são utilizadas as rotinas escritas pelo próprio autor em R. Em ambos capítulos, o autor fornece exemplos ilustrativos ao final dos mesmos. Já no capítulo 8 o autor apresenta de forma bem sucinta os modelos de função de transferência envolvendo 2 ou mais séries, tudo descrito no domínio da freqüência. Interessante observar que nada relativo aos modelos causais no tempo foi mostrado anteriormente, o que, de alguma forma, torna este material um tanto ambicioso e até mesmo desnecessário, especialmente se considerarmos que o público alvo para o qual o livro foi escrito, não necessariamente está familiarizado com a formulação dos modelos de função de transferência no domínio do tempo.

Como conclusão, podemos destacar inicialmente que, com efeito, o objetivo do autor em propor uma obra voltada para o usuário, sem preocupações maiores de rigor nas apresentações da teoria, foi atingido. Nenhum background rígido seria recomendado para uma leitura proveitosa do mesmo. Outro aspecto positivo e que merece destaque é a proposta do autor de utilizar uma linguagem computacional disponível livre na web e o esforço do mesmo em programar todas as rotinas do material teórico, tanto no domínio do tempo (capítulos 1 a 5), quanto do domínio da freqüência (capítulos 6 a 8) nesta linguagem. Ele não utiliza qualquer outro programa computacional de séries temporais. Aliás, todas estas rotinas são apresentadas no ultimo capítulo do livro, onde é também apresentado um pequeno resumo da linguagem R. Como pontos negativos da obra, a ordem um tanto confusa da apresentação dos modelos ARIMA já mencionado acima e, o mais importante, a total falta de cuidado do autor de fazer uma revisão final rigorosa do texto final. Existem alguns erros de impressão e alguns erros que podem até dificultar o entendimento de passagens teóricas, como a já mencionada na página 55. Com certeza, a obra perde muito com estas irregularidades. A obra revisada, será, com certeza, de grande valia e uma alternativa interessante para os leitores que procuram um texto introdutório, porém objetivo e completo em termos de abrangência de modelos para a análise e previsão de séries temporais.

Reinaldo Castro Souza reinaldo@ele.puc-rio.br 